\title{
UMA ANÁLISE DOS APENADOS POR PRESTAÇÃO DE SERVIÇOS E/OU PECUNIÁRIA NO PARANÁ ${ }^{1}$
}

\author{
Helena Nickel \\ Pery Francisco Assis Shikida ${ }^{3}$
}

\section{Resumo}

O objetivo geral desta pesquisa consistiu em analisar, a partir da teoria de Becker (1968), o perfil sociodemográfico e criminal de apenados no âmbito da $4^{a}$ Vara da Justiça Federal de Foz do Iguaçu (ParanáBrasil), cujas penas privativas de liberdade foram substituídas por prestação de serviços à comunidade e/ou prestação pecuniária. Para responder o objetivo da pesquisa, foram realizadas entrevistas, mediante aplicação de questionários com 222 utilizados para a análise descritiva. O perfil dos entrevistados foi, em sua maioria, homens (86,5\%), de cor branca (74,8\%), com faixa etária considerada jovem (entre 18 a 33 anos, perfazendo $55 \%$ ), sendo em grande parte, paranaenses. Destacaram-se, também, o nível de escolaridade situado, mormente, no ensino fundamental (47,3\%), com prática religiosa para 59,5\% dos entrevistados, 40,1\% estava trabalhando e recebendo uma renda de um a dois salários mínimos, sendo o contrabando (em sua maioria de cigarro) o delito de maior ocorrência (52,7\%). A principal motivação para o crime econômico está relacionada com a ideia de ganho fácil/indução de amigos/cobiça, ambição, ganância/inveja/manter o status $(46,1 \%)$.

Palavras-chave: Economia do crime. Pesquisa de campo. Motivação ao crime.

\section{Abstract}

The main goal of this research was to analyze, based on Becker's theory (1968), the sociodemographic and criminal profile of convicted people in the scope of the 4th Federal Court of Foz do Iguaçu (Paraná-Brazil), whose criminal sentences have been replaced by community service and/or pecuniary sanctions. In order to achieve the goal of the research, interviews were carried out through the application of questionnaires to 222 being used for the descriptive analysis. The majority of the interviewees were male $(86.5 \%)$, white (74.8\%), in the young age group (between 18 to 33 years old, totalizing 55\%), being mostly from the Paraná State (paranaenses). One of the remarkable aspects was the level of formal education, attended middle school (47.3\%), with religious practice for $59.5 \%$ of respondents, $40.1 \%$ were working and receiving income between one and two minimum wages, with smuggled goods (mostly cigarettes) being the most frequent offense $(52.7 \%)$. The main motivation for economic crime is related to the idea of easy gain/induction of friends/greed, ambition, avarice/envy/maintaining status (46.1\%).

Key words: Economics of crime. Field research. Motivation to crime.

\footnotetext{
${ }^{1}$ Este trabalho contou com o apoio do Conselho Nacional de Desenvolvimento Científico e Tecnológico (CNPq) e da $4^{\text {a }}$ Vara da Justiça Federal de Foz do Iguaçu. Agradecemos às Instituições supracitadas, em especial, ao Juiz Federal Dr. Matheus Gaspar.

${ }^{2}$ Mestre em Desenvolvimento Regional e Agronegócio pela Universidade Estadual do Oeste do Paraná (UNIOESTE). Rua da Faculdade n ${ }^{\circ}$ 645, Jardim Santa Maria - Toledo, PR. CEP: 85.903-000. E-mail: helenanickel@hotmail.com

${ }^{3}$ Doutor em Economia Aplicada pela ESALQ/USP. Professor Associado da Universidade Estadual do Oeste do Paraná (UNIOESTE). Bolsista de Produtividade em Pesquisa do CNPq. Membro do Conselho Nacional de Política Criminal e Penitenciária. Rua da Faculdade n ${ }^{\circ}$ 645, Jardim Santa Maria - Toledo, PR. CEP: 85.903-000. E-mail: peryshikida@hotmail.com
} 


\section{Resumen}

El objetivo general de esta investigación fue analizar, con base en la teoría de Becker (1968), el perfil sociodemográfico y criminal de los prisioneros dentro del $4^{\circ}$ Tribunal Federal de Foz de Iguazú (ParanáBrasil), cuyas penas (privativas de libertad) fueron reemplazadas por servicios comunitarios y/o beneficios en efectivo. Para responder al objetivo de la investigación, se realizaron entrevistas, mediante la aplicación de cuestionarios con 222 utilizados para el análisis descriptivo. El perfil de los entrevistados fue en su mayoría hombres (86.5\%), blancos $(74.8 \%)$, con un grupo de edad considerado joven (entre 18 y 33 años, que representa el 55\%), siendo, en gran parte, nacidos en el Estado de Paraná. El nivel educativo también se destacó, principalmente en la escuela primaria (47.3\%), práctica religiosa para el $59.5 \%$ de los entrevistados, el $40.1 \%$ trabajaba y recibía de uno o dos salarios mínimos. El contrabando (principalmente cigarrillos) fue el delito más común (52.7\%). La principal motivación del delito económico está relacionada con la idea de ganancia fácil/amigos que inducen el crimen/codicia, ambición, envidia/mantener el "status" $(46,1 \%)$.

Palabras clave: Economía de crimen. Investigación de campo. Motivación al crimen.

\section{INTRODUÇÃO}

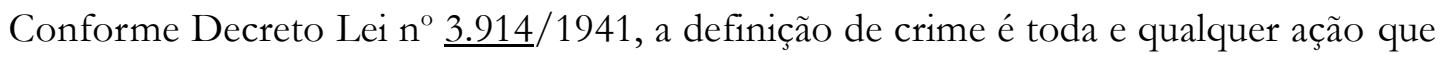
a lei impõe "pena de reclusão ou detenção, quer isoladamente, quer alternativa ou cumulativamente com a pena de multa; contravenção, a infração a que a lei comina, isoladamente, penas de prisão simples ou de multa, ou ambas, alternativa ou cumulativamente" (BRASIL, 2017, p. 485). Ainda de acordo com o Código Penal - CP, art. 59 (BRASIL, 2017, p. 515), a determinação do regime inicial de cumprimento da pena far-se-á com base nos critérios previstos em Lei, dentre os quais: “a) culpabilidade do réu; b) antecedentes; c) conduta social; d) personalidade da pessoa; e) motivo(s) para o crime; f) circunstâncias do delito; g) consequências dessa atividade criminal; h) comportamento da vítima."

Com efeito, quanto mais grave é o crime praticado, mais rigoroso é o tratamento direcionado ao réu. Assim, existe o regime fechado referente às condenações mais graves, destinado aos condenados com pena superior a oito anos ou para os condenados reincidentes cuja pena seja inferior a oito anos, porém superior a quatro; podendo a execução da pena ser em estabelecimento de segurança máxima ou média.

O regime semiaberto é aquele no qual o apenado possui condições de trabalho, sem ser potencialmente ofensivo para a ordem social, podendo trabalhar durante o dia, mas devendo recolher-se ao local de cumprimento da pena - que pode ser uma colônia agrícola, industrial ou estabelecimento similar - durante o período noturno. É aplicável ao condenado não reincidente (primário) cuja pena for superior a quatro anos e não exceda a oito. 

no paraná. DOI: http://dx.doi.org/10.5380/recp.v10i2.68818

O regime aberto é imposto a todo réu condenado a até quatro anos de prisão, desde que não reincidente. Nesse caso, o apenado pode trabalhar durante os dias e recolher-se durante as noites em lugar definido em sentença, podendo ser uma casa de albergado ou outro estabelecimento adequado (por exemplo, sua própria residência).

Frisa-se que as penas privativas de liberdade substituídas por prestação de serviços (à comunidade ou a entidades públicas) e/ou prestação pecuniária possuem, em teoria, caráter pedagógico. Vale ressaltar, de acordo com o CP, que no caso da prestação pecuniária, por exemplo, são necessárias algumas condições como: verificar qual a posição econômica do réu e a extensão dos danos causados à vítima ou seus dependentes (que se habilitaram na fase de execução), caso essa vítima tenha falecido. Pode ocorrer também de a prestação pecuniária ser destinada para entidades de fins sociais.

Esses quesitos, bem como a importância a ser paga, são fixadas pelo juiz, não sendo inferior a um salário mínimo, nem superior a trezentos e sessenta salários mínimos, sendo deduzido do valor de eventual condenação em ação de reparação civil, se coincidentes os beneficiários. No caso da prestação de serviços à comunidade ou entidades públicas, isto é duplamente benéfico, servindo como uma forma de punição e como forma de reeducação do sentenciado, para que este consiga se conscientizar sobre o delito praticado e de suas consequências.

É aplicável às condenações superior a seis meses de privação da liberdade, podendo ser realizada em entidades assistenciais, hospitais, escolas, orfanatos e outros estabelecimentos congêneres, em programas comunitários ou estatais. As tarefas do condenado, entretanto, são atribuídas em consonância com suas aptidões, devendo ser cumpridas à razão de uma hora de tarefa por dia de condenação, fixadas de modo a não prejudicar a sua jornada normal de trabalho. Contudo, se a pena substituída for superior a um ano, é facultado ao condenado cumprir a pena substitutiva em menor tempo, mas nunca inferior à metade da pena privativa de liberdade fixada.

O universo das penas substitutivas e seus resultados práticos ainda são um mistério para os aplicadores do Direito. Na Justiça Federal, cerca de 80\% das condenações são substituídas por prestação de serviços e/ou prestação pecuniária (CNPq, 2018). Apesar disso, são poucas (para não dizer nenhuma) as varas federais que possuem informações sobre a efetividade da prestação de serviço e/ou da prestação pecuniária (exemplo: número de apenados, percentual de penas cumpridas/descumpridas, entidades para as quais os apenados são encaminhados etc.). Assim, este artigo é de interesse para todas as unidades judiciárias do Brasil que possuem competência para a execução de penas alternativas.

O objetivo geral desta pesquisa consiste em analisar o perfil sociodemográfico e criminal de apenados por crimes econômicos no âmbito da $4^{a}$ Vara da Justiça Federal de Foz do Iguaçu 
NICKEL, H.; SHIKIDA, P. F. Uma análise dos apenados por prestação de serviços elou pecuniária no paraná. DOI: http://dx.doi.org/10.5380/recp.v10i2.68818

(Paraná), cujas penas privativas de liberdade foram substituídas por prestação de serviços e/ou prestação pecuniária, mediante aplicação de questionários/entrevistas. Cabe ressaltar que este trabalho é fruto de uma dissertação, dessa forma, será apresentado apenas um recorte dos resultados que foram obtidos (NICKEL, 2019).

Este artigo contém cinco seções, incluindo esta introdução (1). São feitos, na sequência, uma concisa revisão sobre o referencial teórico (2) e metodologia (3). A seção seguinte trata da análise dos resultados e discussão (4) e as considerações finais (5) completam o artigo.

\section{REFERENCIAL TEÓRICO}

\subsection{TEORIA DP BECKER E O INSTITUCIONALISMO DA ESCOLHA RACIONAL}

Gary Becker foi um dos economistas que mais explorou as decisões do comportamento humano individual pelo prisma da economia. Seu primeiro estudo de maior impacto foi sobre a discriminação racial no mercado de trabalho norte-americano, que culminou em sua tese de doutoramento na Universidade de Chicago em 1957. Em 1962, abordou a temática do investimento em capital humano como elemento de extrema importância no desenvolvimento das nações. A partir da década de 1970, Becker passou a redirecionar seus estudos para o comportamento familiar (como casamento, divórcio, fertilidade e filhos). Contudo, foi em 1968 que publicou um de seus mais importantes trabalhos: "Crime and punishment: an economic approach", desenvolvendo uma abordagem econômica para o crime na qual os indivíduos respondem racionalmente a incentivos tanto positivos como negativos no cometimento de um ilícito (BALBINOTTO NETO, 1993). Essa abordagem, posteriormente consolidada como Teoria Econômica do Crime, servirá de sustentação teórica para o presente estudo.

Para Becker (1968), um indivíduo, diante da possibilidade de cometer um crime econômico (crime com finalidade de lucro financeiro), age racionalmente no sentido de maximização de seus benefícios, realizando uma avaliação entre custos e ganhos. Os ganhos são representados pelo montante financeiro a ser auferido com aquela prática criminosa e os custos estariam enquadrados em 5 variáveis principais: 1) probabilidade de apreensão ou a chance de ser surpreendido durante o delito; 2) tamanho da pena a ser cumprida caso seja preso e condenado; 3) custos de oportunidade, que representam quanto o indivíduo poderia estar ganhando no mercado lícito; 4) custos morais, que dizem respeito ao valor da imagem e reputação daquele indivíduo; e 5) os custos do planejamento e da operacionalização do crime em si. 
Para Cerqueira e Lobão (2004, p. 247), o entendimento de Becker pode ser sintetizado da seguinte forma:

\begin{abstract}
A decisão de cometer ou não o crime resultaria de um processo de maximização da utilidade esperada, em que o indivíduo confrontaria, de um lado, os potenciais ganhos resultantes da ação criminosa, o valor da punição e as probabilidades de detenção e aprisionamento associadas e, de outro, o custo de oportunidade de cometer crimes, traduzido pelo salário alternativo no mercado de trabalho.
\end{abstract}

No estudo do economista Becker (1968), Balbinotto Neto (2003, p.1) destaca que "para os economistas, o comportamento criminoso não é visto como uma atitude simplesmente emotiva, irracional ou antissocial, mas sim como uma atividade eminentemente racional". Salienta o autor que os infratores se comportam às vezes de forma negativa e às vezes positiva aos incentivos e gastos públicos e privados. A aplicação da lei, na tentativa da sua eficácia, tenta evitar, prevenir ou convencer o infrator de que o crime é negativo, aspirando assim dissuadi-lo.

Nessa linha, vale citar também o institucionalismo da escolha racional, em que:

[...] there is only rational behavior, conditioned on expectations about the behavior and reactions of others. When these expectations about others' behavior take on a particularly clear and concrete form across individuals, when they apply to situations that recur over a long period of time, and specially when they involve highly variegated and specific expectations about the different roles of different actors in determining what actions others should take [...] (SHEPSLE, 2008, p. 26).

Nesse caso, a racionalidade do agente individual estrutura-se por meio de ações otimizadoras em um contexto maior de "regras do jogo" no qual, frisa-se, outros agentes, também racionais, atuam. Dessa forma, as instituições atuam como "exogenous constrains or as an exogenously givem game form" (SHEPSLE, 2008, p. 24).

\title{
2.2. TEORIA DAS PENAS
}

\subsubsection{DEFINIÇÃO E ESPÉCIES}

Segundo Santos (2001, p. 182), conceitua-se pena como "uma imposição da perda ou diminuição de um bem jurídico, prevista em lei e aplicada, pelo órgão judiciário, a quem praticou ilícito penal. No Brasil, elas podem ser: privativas de liberdade; restritivas de direito; de multa".

Da mesma forma para Bitencourt (2017), a origem da pena é antiga como a história da humanidade, sendo difícil situar suas raízes. Indubitavelmente é muito remota a origem das relações entre pessoas. 

no paraná. DOI: http://dx.doi.org/10.5380/recp.v10i2.68818

Na doutrina contemporânea, Greco (2019) conceitua que a pena é decorrência natural imposta pelo Estado quando uma pessoa comete uma infração. Quando a pessoa realiza um fato típico, ilícito e culpável, o Estado vale-se do seu poder de ius puniendə’.

Masson (2020) explica que a pena é uma sanção aflitiva, aplicada pelo Estado, mediante ação penal, ao autor de um ato ilícito e cujo fim é evitar novos delitos ou contravenções penais.

Como função da pena, Gomes (2000, p. 40) destaca que "a pena ou qualquer outra resposta estatal ao delito, destarte, acaba assumindo um determinado papel”. No modelo clássico, o castigo penal tinha como objetivo prevenir novos delitos, no modelo contemporâneo, a pena não só tenta impedir novas infrações, mas busca a ressocialização do criminoso observando seus direitos para evitar a reincidência criminal pelas vias legais.

Apontam Mirabete e Fabbrini (2018) que já se pregava a ideia de que se deveria conferir fins superiores à pena, como a prevenção geral e a defesa do Estado. Não obstante, uma concepção pedagógica da pena teve origem na Grécia clássica entre os sofistas.

Em consonância com a doutrina exposta, Berger (2008, p. 70) enfatiza que o Estado, além de aplicar a lei penal ao criminoso, também detém o monopólio da administração pública para garantir a execução de uma pena pela justiça.

Carnelutti (2006, p. 103) explica que a pena não é somente uma punição ao criminoso, o que se quer apresentar com este estudo, mas uma forma de reprovação a pretendentes, pois "dizem, facilmente, que a pena não serve somente para a redenção do culpado, mas também para a advertência dos outros, que poderiam ser tentados a delinquir e por isso deve os assustar; e não é este um discurso que deva se tomar por chacota", impondo ao infrator a tese de que a pena tem a função repressiva e preventiva. Aquela condenação é apenas direcionada ao culpado, não condenando previamente cidadãos de bem, "e não há entre esses dois aspectos do instituto, possibilidade de conciliação" (CARNELUTTI 2006, p. 103).

Definição dada por Santos (2001, p. 182), a pena é uma restrição de direitos e diminuição de bens jurídicos imposta aos que cometem atos ilícitos, sendo a pena "uma imposição da perda ou diminuição de um bem jurídico, prevista em lei e aplicada, pelo órgão judiciário, a quem praticou ilícito penal. No Brasil, elas podem ser: privativas de liberdade; restritivas de direitos; de multa".

Realça Nucci (2019) que desde o início dos tempos as pessoas violam as regras de coexistência, ferindo os outros e também a própria comunidade/sociedade onde se insere, tornando necessária a aplicação de um castigo/punição, ou seja, uma sentença judicial efetiva às penas. 

no paraná. DOI: http://dx.doi.org/10.5380/recp.v10i2.68818

Nas normas legais brasileiras, as espécies de penas estão elencadas no art. 32, do CP (Redação dada pela Lei no 7.209, de 11.7.1984), cabendo ao Estado (juiz) sua aplicação: "I privativas de liberdade; II - restritivas de direitos; e, III - de multa” (BRASIL, 2017, p. 512).

Da Lei de Execução Penal (LEP) no art. 110, o representante do Estado, com base no juízo de direito, em decisão fundamentada, “o Juiz, na sentença, estabelecerá o regime no qual o condenado iniciará o cumprimento da pena privativa de liberdade, observado o disposto no art. 33 e seus parágrafos do CP” (BRASIL, 2017, p. 512).

Não esquecendo que em uma decisão judicial, toda a "sentença sem motivação é nula" (art. 93, IX, Constituição Federal c/c art. 564, III, CPP) (BRASIL, 2017, p. 643).

É o que preconizava Beccaria (1997, p. 61), “um homem não pode ser chamado de culpado antes da sentença do juiz e a sociedade só lhe pode retirar a proteção pública após ter decidido que ele violou os pactos por meio dos quais ela foi outorgada", condenado por meio de uma sentença motivada o infrator, imputando assim uma pena coercitiva e reparadora ao mal causado à sociedade.

\subsubsection{PRESTAÇÃO DE SERVIÕ À COMUNIDADE E/OU PECUNIÁRIA}

Bitencourt (2019) postula que as penas substitutivas à prisão, na modalidade de prestação de serviços à comunidade, tiveram início com o CP soviético de 1926. Em seguida, foram reproduzidas nos ordenamentos penais do leste europeu e, logo após, incorporadas ao Ocidente: Bélgica (1963), França (1970), Alemanha (1975), Itália (1975), Portugal (1977), Espanha e Brasil (1980).

No cumprimento da pena pelo condenado, a prestação de serviços à comunidade ou o pagamento em dinheiro são obrigações que intentam auxiliar na ressocialização do infrator, com base na Lei no 7.210, de 1984, que rege a Lei de Execução Penal, sendo que, além de punir, objetiva também prevenir novos delitos. Como prevê o art. 46 do CP, os serviços em benefício da comunidade devem constituir-se na atribuição de tarefas gratuitas em áreas adequadas às aptidões (BRASIL, 2017, p. 514).

A pena pecuniária está elencada no art. $45, \sqrt{\Omega} 1^{\circ}$ do $\mathrm{CP}$ :

A prestação pecuniária consiste no pagamento em dinheiro a vítima, a seus dependentes ou à entidade pública ou privada, com destinação social de importância fixada pelo juiz, não inferior a um nem superior a trezentos e sessenta salários mínimos, o valor pago será deduzido do montante de eventual condenação em ação de reparação civil, se coincidentes os beneficiários (BRASIL, 2017, p. 514). 

no paraná. DOI: http://dx.doi.org/10.5380/recp.v10i2.68818

Em concordância com a norma supra sobre a obrigação pecuniária, na decisão do Tribunal Regional Federal da $3^{a}$ Região, deve ser observado a condição financeira do apenado na substituição da pena em prestação pecuniária, "esta deve ser fixada levando em consideração a capacidade econômica da condenada, de modo a não colocar em risco a manutenção de sua subsistência” (MOREIRA, 2015, p. 1).

Em recursos repetitivos, o Supremo Tribunal de Justiça nos autos de Recurso Especial no 1.107.314/PR, decidiu que a prestação de serviço comunitário não é possível na pena em regime aberto quando substitutiva, para evitar a dúplice sanção (BRASIL, 2010).

Shecaira (2008, p. 199) defende que a prestação de serviços à comunidade tem que ser a mais importante pena alternativa às penas institucionais, pois alerta que causa no "infrator a ideia de responsabilidade, de apego às normas comunitárias, de respeito pelo trabalho, bem como produz na comunidade uma sensação de obediência às regras, que é fundamental para a confiança coletiva".

Na fase da execução da pena pelo condenado, o art. 148, da LEP fundamenta ao juiz "alterar a forma de cumprimento das penas de prestação de serviços à comunidade e de limitação de fim de semana, ajustando-se às condições pessoais do condenado e às características do estabelecimento, da entidade ou do programa comunitário ou estatal” (BRASIL, 2017, p. 1539).

Para o conhecimento judicial, "a entidade beneficiada com a prestação de serviços encaminhará mensalmente, ao Juiz da execução, relatório circunstanciado das atividades do condenado, bem como, a qualquer tempo, comunicação sobre ausência ou falta disciplinar”, de acordo com a LEP (BRASIL, 2017, p. 1539).

Quanto às entidades beneficiadas com a prestação de serviços à comunidade, Bitencourt (2019) lembra que as que visam lucro não estão credenciadas no Poder Judiciário, pois poderia ocorrer a exploração da mão de obra gratuita, como também o enriquecimento sem uma contraprestação social. Bitencourt (2019) ainda ressalta que os trabalhos têm a função de ressocializar o apenado com a prestação de forma não remunerada, o que poderia agravar o custo econômico dos órgãos públicos com as entidades que ajudam na reintegração social.

Com o objetivo da ressocialização, educando ou reeducando o infrator na execução da pena, a Lei de Execução Penal (LEP) tem como escopo o cumprimento de pena e a reintegração social do apenado, que é inseparável da execução da sanção penal. Dessa forma, uma modalidade de cumprimento de pena deve ter concomitância dos dois objetivos (castigo e a reintegração social) para estar em conformidade com a legalidade (BITENCOURT, 2019).

Cabe destacar a pesquisa realizada na Vara de Execução da Comarca de Porto Velho/RO (2019) como exemplo onde a modalidade de pena alternativa mais aplicada, em 80\%, foi a da 
prestação de serviços à comunidade. Já a prestação pecuniária, foi aplicada em 15\%, restando apenas $5 \%$ para as demais alternativas.

O objetivo principal da prestação de serviços à comunidade (PASTORE, 2011), como pena de ressocialização, é tentar diminuir a criminalidade, retribuindo benefícios à sociedade, compensando prejuízos causados pelos delitos e conduzindo o apenado ao meio social, podendo refletir e corrigir as suas práticas ilícitas.

\section{METODOLOGIA}

A presente pesquisa tem abordagem qualitativa, uma vez que visa apresentar resultados de estatística descritiva. A modalidade foi multicaso que, segundo Gil (2000), é indicado para situações com múltiplas variáveis explicativas de um fenômeno.

Esse tipo de abordagem de pesquisa também foi utilizado por Schlemper (2018). Esse autor ainda ressalta o fato de os métodos qualitativos e quantitativos não serem antagônicos ou excludentes, mas complementares, bem como a natureza da pesquisa em economia do crime, baseada em dados primários, ser complexa e com diversas opiniões de grupos sociais.

Como o objetivo deste estudo é analisar o perfil social e criminal de apenados na prática de crimes de ordem econômica (da $4^{a}$ Vara da Justiça Federal de Foz do Iguaçu, Paraná), cujas penas privativas de liberdade foram substituídas por prestação de serviços e/ou prestação pecuniária, mediante aplicação de questionários/entrevistas, bem como analisar se a prestação de serviços à comunidade ou a entidades públicas está sendo efetivamente realizada, essa modalidade de pesquisa se mostrou pertinente, além de que várias entidades receptoras destas prestações de serviço foram foco do estudo.

A pesquisa de campo ocorreu na sede da $4^{a}$ Vara da Justiça Federal de Foz do Iguaçu, no Paraná, em 18 entidades parceiras, para 272 detentos que prestam atualmente serviços à comunidade, como pena alternativa à privação de liberdade. A relação dos nomes dos 272 apenados, bem como o cronograma das entrevistas, foram elaborados e disponibilizados por esta Instituição (seguindo código de ética, não será apresentada aqui por razões de sigilo e segurança). ${ }^{4}$

No entanto, foram utilizados 222 questionários para a análise descritiva, dado que, do total de questionários aplicados (272), 111 apenados responderam que a substituição da pena em prestação de serviço não ressocializa e 161 disseram que ressocializa. Dessa forma, para equalizar

\footnotetext{
${ }^{4}$ Este estudo é oriundo de uma parceria entre a $4^{\mathrm{a}}$ Vara da Justiça Federal de Foz do Iguaçu (PR), que aprovou institucionalmente o teor deste estudo (em acordo com a ética de pesquisa), com Programa de Pós-Graduação em Desenvolvimento Regional e Agronegócio (PGDRA) - Universidade Estadual do Oeste do Paraná (UNIOESTE).
} 

no paraná. DOI: http://dx.doi.org/10.5380/recp.v10i2.68818

o número de questionários em respostas positivas e negativas, excluiu-se 50 questionários com resposta positiva, de forma aleatória pelo software SPSS. Para efeito de tipificação de condenações, dos 222 pesquisados, 161 (72,5\%) foram de prestação de serviços e pecúnia (conjuntamente), enquanto $61(27,5 \%)$ só prestação de serviços.

As 18 entidades receptoras da prestação de serviços executados pelos apenados são apresentadas na Quadro 1.

Quadro 1 - Entidades Receptoras da Prestação de Serviços

\begin{tabular}{|c|c|}
\hline Número & Entidade \\
\hline 1 & Guarda Municipal de Foz do Iguaçu \\
\hline 2 & Instituto de Atletismo de Foz do Iguaçu \\
\hline 3 & Escola Municipal Írio Manganelli \\
\hline 4 & $6^{a} \operatorname{SDP}$ \\
\hline 5 & $9^{\circ}$ Grupamento de Bombeiros \\
\hline 6 & Guarda Mirim de Foz do Iguaçu \\
\hline 7 & $14^{\circ}$ Batalhão de Polícia Militar \\
\hline 8 & Colégio Estadual Barão do Rio Branco \\
\hline 9 & Associação Fraternidade Aliança - AFA \\
\hline 10 & Colégio Estadual Dom Manoel Konner \\
\hline 11 & Colégio Estadual Almiro Sartori \\
\hline 12 & Colégio Estadual Tancredo Neves \\
\hline 13 & UNIOESTE - campus Foz \\
\hline 14 & Associação um Chute para o Futuro \\
\hline 15 & Núcleo de apoio Judiciário e administrativo da Justiça federal \\
\hline 16 & Escola Municipal Jardim Naipi \\
\hline 17 & Centro Educação Infantil Vicentino Nossa Senhora da Conceição \\
\hline 18 & Colégio da Polícia Militar - Mitre \\
\hline
\end{tabular}
Fonte: elaborado pelos autores (2019).

O questionário utilizado nas entrevistas foi baseado em estudo pioneiro de Borilli (2005), que recebeu modificações e avanços em Schlemper (2018), mas que foi adaptado para atender aos objetivos da presente pesquisa. Este instrumento de coleta de dados é composto por 109 questões - divididos em 7 blocos (NICKEL, 2019).

Dados gerais: desenvolve uma caraterização geral do entrevistado nos aspectos pessoais, demográficos e comportamentais.

Tipologia e aspectos econômicos do crime: além de tipificar o crime, cometido por cada apenado e sua motivação, este bloco de questões aborda os aspectos de custo e retorno do crime, elementos fundamentais da teoria econômica do crime de Becker (1968).

Maioridade penal: confronta a opinião dos entrevistados com relação aos aspectos da maioridade penal no Brasil (18 anos de idade) e a possibilidade de sua (controversa) redução para 16 anos. Investiga ainda os efeitos da dissuasão com relação à idade dos detentos. 

no paraná. DOI: http://dx.doi.org/10.5380/recp.v10i2.68818

Outras questões: trata da percepção dos detentos com relação à atuação das facções/organizações criminosas e, também, sobre o mercado de drogas ilícitas e sua influência no mundo do crime (são questões que, embora distantes do eixo principal da presente pesquisa, permitem revelar um quadro melhor do entrevistado).

Sobre a pena privativa de liberdade, substituída por prestação de serviços: esse bloco abrange um dos pontos principais do projeto em questão: se a prestação de serviços à comunidade ou a entidades públicas está sendo efetivamente realizado e se contribui para ressocializar o condenado, se o serviço prestado por ele é útil à sociedade, se houve demora entre a prática do crime por ele praticado até a aplicação da pena.

Sobre a pena privativa de liberdade, substituída por prestação pecuniária: aborda, junto aos apenados, se essa pena contribui para ressocializar quem cometeu os delitos, se são expressivos os valores das penas de multas pecuniárias impostas para quem cometeu tal delito, entre outras questões. Essa pena financeira substitui a pena de reclusão, fazendo com que o apenado fique em liberdade assistida, sendo muitas vezes aplicada simultaneamente com a pena de prestação de serviços à comunidade.

Entidades receptoras da prestação de serviços: percepção das entidades, nas quais os apenados cumprem a prestação de serviços, sobre a eficácia da ressocialização desta modalidade de pena, pontos positivos e negativos dessa interação etc.

Houve, durante o mês de março de 2019, a aplicação de pré-testes com o questionário piloto que, a partir desse momento, sofreu aperfeiçoamentos até chegar ao resultado final - vide: Nickel (2019). Também foi feito o treinamento dessa pesquisadora com esse procedimento de aplicação de perguntas e interação com os entrevistados (postura ética). ${ }^{5}$

O procedimento de coleta de dados seguiu o mesmo procedimento de como se comportar nesse tipo pesquisa de campo, citado por Schlemper (2018) em sua tese de doutorado, no que tange à vestimenta, postura, gestuais e linguagem no contato com o apenado.

Para entrada na $4^{a}$ Vara da Justiça Federal de Foz do Iguaçu/PR, convém citar, todos os pesquisadores passaram pelos procedimentos padrão de revista e porta giratória, levando consigo apenas as folhas impressas dos questionários e um lápis cada um. A coleta de dados compreendeu todo o primeiro semestre de 2019, em conformidade com agenda previamente organizada por equipe de profissionais da $4^{\text {a }}$ Vara.

\footnotetext{
${ }^{5}$ Salienta-se que este instrumento de coleta dos dados é um componente de um projeto amplo, aprovado pelo Conselho Nacional de Desenvolvimento Científico e Tecnológico (CNPq, 2018) e pela $4^{a}$ Vara da Justiça Federal de Foz do Iguaçu, sob a supervisão do Doutor Juiz Federal Matheus Gaspar.
} 

no paraná. DOI: http://dx.doi.org/10.5380/recp.v10i2.68818

A estatística descritiva utilizada neste trabalho tem a função de produzir uma caracterização dos entrevistados em termos de condições socioeconômicas, principais tipos de crime, motivação da migração para o mercado ilícito e relação custo/retorno da atividade criminosa.

\section{ANÁLISE DOS RESULTADOS}

Os resultados obtidos nesta pesquisa são apresentados conforme questionários aplicados (dados gerais, perfil socioeconômico, perfil criminal, motivos da prática e o temor criminal).

Convém rememorar que o objetivo geral desta pesquisa consiste em analisar o perfil sociodemográfico (item 4.1) e criminal (item 4.2) da prática ilícita de apenados em crimes de ordem econômica, no âmbito da $4^{a}$ Vara da Justiça Federal de Foz do Iguaçu (PR), cujas penas privativas de liberdade foram substituídas por prestação de serviços e/ou prestação pecuniária, mediante aplicação de questionários/entrevistas.

\subsection{PERFIL SOCIODEMOGRÁFICO}

Como característica desse perfil, ficou comprovado que 86,5\% são homens e 13,5\% são mulheres. Com relação à cor, 74,8\% se declararam brancos(as), 11,3\% pardos(as), 9,9\% negros(as), 1,8\% amarelos(as), 1,4\% mulatos(as) e 0,9\% mestiços(as).

Em relação à idade dos pesquisados, houve uma distribuição em que se destacaram as seguintes faixas etárias: 18 anos (0,5\%); 19 a 23 anos (18\%); 24 a 28 anos (16,7\%); 29 a 33 anos (19,8\%); 34 a 38 anos (20,7\%); 39 a 43 anos (10,4\%); 44 a 48 anos (5\%) e acima de 49 anos (9\%).

A maioria dos entrevistados é paranaense (71,2\%), seguido de gaúchos (5\%), catarinenses (4,5\%), paulistas $(3,6 \%)$, baianos e cariocas $(1,4 \%$ cada), pernambucanos e sul mato-grossenses ( $0,9 \%$ cada), outros estados $(2,7 \%)$ e outras nacionalidades $(8,6 \%)$. A maioria é de origem urbana (79,3\%), isto é, nasceram em áreas urbanas, sendo 20,7\% originários da área rural.

Foi perguntado se o apenado acredita em Deus, como resposta 99,5\% disseram acreditar e somente uma pessoa afirmou não acreditar em Deus (0,5\%). As religiões com maiores frequências foram: católica (59\%); evangélica (31,1\%); muçulmana (1,4\%); espírita $(0,9 \%)$; protestante $(0,5 \%)$; e sem religião $(7,2 \%)$. Dos que afirmaram ter uma religião, 59,5\% disseram praticar, isso quer dizer que 40,5\% não praticam a religião que dizem ter. Constatou-se também que 82,9\% nunca mudaram de religião e $17,1 \%$ mudaram. 

no paraná. DOI: http://dx.doi.org/10.5380/recp.v10i2.68818

Como trava moral, apontado por Shikida, Araujo Junior e Shikida (2005), a prática religiosa é um fator relevante do tripé da organização social, pois pode alterar ou não a ação de delinquentes, porquanto, há indícios de que a religião também influencia no grau de violência usado pelo agente criminoso.

Sobre o nível de escolaridade, constatou-se: o ensino fundamental completo $(28,4 \%)$; fundamental incompleto (18,9\%); ensino médio completo (32\%); médio incompleto $(8,6 \%)$; superior completo $(8,6 \%)$; superior incompleto $(3,2 \%)$; e sem instrução $(0,5 \%)$. Segundo Beccaria (2007) e Schlemper (2018), a educação é também uma das bases para evitar e/ou diminuir a prática criminosa.

O motivo (pode ser mais do que um) mais relevante para a interrupção dos estudos foi a necessidade de contribuir com a renda familiar (61,7\%), o que denota que a maioria das pessoas entrevistadas vieram de famílias com restrições financeiras. Não obstante, esse nível de detalhamento merecia mais questionamentos não possíveis diante do foco deste estudo. Em seguida, apareceu o casamento/concubinato $(10,4 \%)$, que também pode se relacionar com a motivação financeira, pois, com o casamento a pessoa, a fortiori, teve que assumir maiores responsabilidades materiais. $\mathrm{Na}$ opção outros, dentre os entrevistados, tiveram pessoas que abandonaram os estudos devido à guerra (no Líbano), dificuldade financeira, por motivo de doença, custo de educação elevado, falta de tempo e porque tiveram filhos.

Com relação aos números apresentados, o motivo pelo qual o apenado parou de estudar está relacionado, em muitos casos, com o ato ilegal pela desqualificação profissional e baixo rendimento financeiro. Fantinel (2016) destacou que a educação é ponto importante para evitar a marginalização e até mesmo para recuperar o indivíduo ao convívio social lícito. Para Zaluar (2004, p. 201), “[...] estão se reunindo em galeras ou quadrilhas, os homens jovens [...] que, após várias repetências, deixaram a escola e não conseguiram o nível educacional cada vez mais necessário no mercado de trabalho da economia globalizada".

Sobre o estado civil das pessoas pesquisadas, os mais frequentes foram: amasiado (45,5\%); casado (25,2\%); solteiro (23\%); divorciado (4,1\%); separado (1,4\%); e viúvo (0,9\%). Também foi questionado sobre quantas uniões conjugais foram desfeitas, constatando entre os pesquisados que 25,7\% disseram que já havia desfeito outra(s) união(ões) e 74,3\% afirmaram que não tiveram outras uniões desfeitas.

Sobre a composição familiar à época do crime, ficou assim distribuída: esposa e filhos (52,3\%); esposa (17,6\%); pai, mãe e irmãos (8,1\%); sozinho (6,8\%); filhos (4,5\%); mãe (3,6\%); mãe e irmãos (2,3\%); pai e mãe (1,8\%); pai (1,4\%); irmãos $(0,5 \%)$; pai e irmãos $(0,5 \%)$; e outros $(0,9 \%)$. Observou-se, também, que os filhos permanecem em maior percentual com a genitora, quando os 
NICKEL, H.; SHIKIDA, P. F. Uma análise dos apenados por prestação de serviços elou pecuniária no paraná. DOI: http://dx.doi.org/10.5380/recp.v10i2.68818

pais são separados. Outrossim, na composição familiar que o apenado convivia na época do crime com esposa(o) e filhos, o percentual com um filho foi de $21,2 \%$; dois filhos $20,7 \%$; três filhos $8,6 \%$; quatro filhos $4,1 \%$; cinco filhos $0,9 \%$; e sem filhos $44,6 \%$.

No contexto familiar, foi questionado se os apenados viviam em harmonia na época da prática do crime, $86,5 \%$ disseram que viviam em harmonia, enquanto 13,5\% dos apenados disseram que não havia harmonia familiar. Outro fator importante foi a questão da violência doméstica, $76,6 \%$ dos respondentes disseram não ter sofrido violência na esfera familiar, enquanto $23,4 \%$ sim. Esse resultado apontado pela frequência de respostas sinaliza para uma situação, teoricamente, mais harmônica entre os pesquisados. Porém, mesmo sendo menores os percentuais de indicadores de desequilíbrio familiar, esse assunto merece preocupação das autoridades por evidenciar um padrão de comportamento de relações abusivas por parte de uma pessoa contra outra em um contexto doméstico.

Com relação à ocupação dos pais, os entrevistados disseram que os dois estavam trabalhando (26,1\%); só o pai trabalhava (24,3\%); aposentados $(23,9 \%)$; só a mãe trabalhava $(11,3 \%)$; ninguém trabalhava $(9,9 \%)$; e não souberam responder $(4,5 \%)$.

Quanto à escolaridade dos pais dos pesquisados, muitos não souberam precisar se estes terminaram ou não. Em função disso, os percentuais a seguir compreendem a etapa do ensino, mas não especificam sua conclusão. Assim, as respostas mais frequentes para o pai foram: ensino fundamental (36,5\%); sem instrução (34,7\%); ensino médio (8,1\%); superior (1,4\%); e sem resposta (19,4\%). Com relação à mãe: ensino fundamental (42,3\%); sem instrução (38,7\%); ensino médio $(8,1 \%)$; superior $(2,7 \%)$; e sem resposta $(8,1 \%)$. Cabe ressaltar que os entrevistados não responderam ou não sabiam qual a escolaridade do pai, tendo em vista que, em muitos casos, houve o abandono do lar.

Questionados sobre o estado civil dos pais na época do crime, 59,9\% disseram que estes já estavam separados e 40,1\% disseram que os pais estavam casados. Tal resultado mostra que parcela dessas pessoas vêm de uma família com histórico de separação, ocorrida ainda na fase juvenil.

Em relação ao antecedente criminal na família, $71,2 \%$ disseram que não havia esse tipo de antecedente e $28,8 \%$ disseram que tinha algum familiar com antecedente criminal.

O aspecto da estruturação familiar, estado civil e violência familiar, antecedente criminal - guardadas as devidas considerações de Shikida (2005), Borilli (2005) e Schlemper (2018) - sinaliza alguns pontos preocupantes, mesmo sem percentuais majoritários em alguns casos, como para o desequilíbrio familiar e antecedente criminal no seio da família. 
Ao serem questionados se faziam uso de bebida alcoólica, se fumavam e/ou faziam uso de drogas ilícitas, na época do crime, 51,8\% disseram que bebiam; 74,3\% disseram não fumar cigarros; e 95,5\% afirmaram não fazer uso de drogas ilícitas. O mesmo percentual, 51,8\%, disseram que ainda bebem e a percentagem de não fumantes aumentou para 79,7\%, aumentou também a percentagem dos não usuários de drogas ilícitas (99,1\%). Assim, pode-se dizer que houve um maior discernimento dos entrevistados no tocante aos usos supracitados.

Sobre o fato de estarem ou não trabalhando, 49,1\% disseram que não, enquanto 50,9\% disseram que sim, desses que disseram que $\operatorname{sim}, 86 \%$ não tinham carteira assinada e somente $14 \%$ disseram que tinham. Tal quadro denota um elevado índice de desemprego e de informalidade.

Da renda mensal lícita na época do crime, destacam-se as seguintes faixas: sem renda 43,2\%; de um a dois salários mínimos 28,8\%; de dois a quatro salários mínimos $23 \%$; de cinco a sete $2,7 \%$; de oito a dez $0,5 \%$; e acima de dez $1,8 \%$. A questão envolvendo a propriedade de bens imóveis revelou que $41,9 \%$ tinham casa própria, $57,7 \%$ não tinham, enquanto $0,5 \%$ não responderam.

Como corolário, o perfil sociodemográfico dos apenados pode ser assim descrito: a maioria homem; de cor branca; com faixa etária considerada jovem (entre 18 a 33 anos, perfazendo 55\%); de origem urbana; acredita em Deus, com maioria de religião católica, mas, nem todos praticantes (seja de que religião for); possui ensino fundamental na faixa do completo e incompleto (47,3\%); teve como motivo para a interrupção dos estudos a necessidade de contribuir com a renda familiar; morava junto com esposa e filhos; e vivia em harmonia familiar. Um pouco mais da metade dos entrevistados estava trabalhando, mas não tinha carteira assinada e ganhava entre um e quatro salários mínimos (51,8\%). Em relação à sua vida pregressa, a maioria fazia uso de bebida alcóolica, porém, a maioria não fumava nem usava drogas ilícitas. Cumpre dizer, em cotejo com a revisão de literatura, que tal quadro também se assemelha com os obtidos por Borilli (2005), Shikida e Brogliatto (2008) e Schlemper (2018) em suas respectivas pesquisas de campo.

\subsection{PERFIL CRIMINAL}

Nesta seção, são discutidos os resultados relativos ao perfil criminal dos entrevistados e o tipo de crime econômico.

A Tabela 1 evidencia a tipologia dos crimes cometidos pelos pesquisados. Os crimes apresentados estão no formato agregado por tipo, portanto terá uma percentagem maior que 100\% visto que o entrevistado pode ter cometido mais de um delito. Esse resultado sinaliza para um fato "curioso", qual seja, a do delinquente "flex" não especializado em apenas um delito, mas passível 
NICKEL, H.; SHIKIDA, P. F. Uma análise dos apenados por prestação de serviços elou pecuniária no paraná. DOI: http://dx.doi.org/10.5380/recp.v10i2.68818

de migração para aquele que mais retorno econômico trouxer. O contrabando - importar ou exportar mercadoria proibida (em sua maioria de cigarro) - teve 52,7\% de incidência, o descaminho teve 34,2\%, seguidos do tráfico de drogas $(7,2 \%)$ e a sonegação fiscal com $6,3 \%$. O delito de descaminho está descrito no art. 334 do CP, quando "iludir, no todo ou em parte, o pagamento de direito ou imposto devido pela entrada, pela saída ou pelo consumo de mercadoria”. O ato ilícito de contrabando está no art. 334-A do CP (BRASIL, 2017, p. 548).

Tabela 1 - Tipo do crime cometido

\begin{tabular}{c|c}
\hline \hline Tipo de crime & Percentual de ocorrência \\
\hline Contrabando & 52,7 \\
\hline Descaminho & 34,2 \\
\hline Tráfico de drogas & 7,2 \\
\hline Sonegação fiscal & 6,3 \\
\hline Lavagem de dinheiro & 2,7 \\
\hline Crime de telecomunicação & 2,7 \\
\hline Documentos falsos & 1,8 \\
\hline Moeda falsa & 1,8 \\
\hline Porte de arma & 1,8 \\
\hline Peculato & 1,8 \\
\hline Evasão de divisas & 1,4 \\
\hline Direitos autorais & 0,9 \\
\hline Estelionato & 0,9 \\
\hline Falso testemunho & 0,9 \\
\hline Falsidade ideológica & 0,9 \\
\hline Crime contra a fauna & 0,5 \\
\hline Receptação & 0,5 \\
\hline Formação de quadrilha & 0,5 \\
\hline Roubo & 0,5 \\
\hline Furto & 0,5 \\
\hline Fonte: resultados da pesquisa & \\
\hline \hline
\end{tabular}

A Tabela 2 detalha as principais motivações da execução do crime econômico pelos entrevistados (novamente, o percentual total supera os 100\% devido a observância de mais de uma resposta). A principal motivação para o crime econômico está relacionada com o bloco de ideias de ganho fácil/indução de amigos/cobiça, ambição, ganância/inveja/manter o status (46,1\%). Ajudar no orçamento familiar, pois estava desempregado, teve a ocorrência de 36\%, seguida pela dificuldade financeira/endividamento $(26,1 \%)$ e ajudar no orçamento familiar, mas estando empregado (12,6\%). As demais ocorrências ficaram abaixo da casa dos dois dígitos.

Tabela 2 - Quais os motivos da prática criminosa

\begin{tabular}{c|c}
\hline \hline Motivo para a prática da atividade criminosa & $\%$ de ocorrência \\
\hline $\begin{array}{c}\text { Ideia de ganho fácil/indução de amigos/cobiça, ambição, ganância/inveja/manter o } \\
\text { status }\end{array}$ & 46,8 \\
\hline
\end{tabular}



no paraná. DOI: http://dx.doi.org/10.5380/recp.v10i2.68818

\begin{tabular}{c|c}
\hline Ajudar no orçamento familiar/estava desempregado & 36,0 \\
\hline Dificuldade financeira/endividamento & 26,1 \\
\hline Ajudar no orçamento familiar/estava empregado & 12,6 \\
\hline Falta de estrutura familiar/inconsequência e desejo de aventura & 3,6 \\
\hline Sem informação (não sabia que era crime) & 3,6 \\
\hline Diz-se inocente & 1,8 \\
\hline Manter o sustento e vício & 0,5 \\
\hline Motivos fúteis (embriaguez e falta de perspectiva) & 0,5 \\
\hline Sem resposta & 1,4 \\
\hline Outros & 1,4 \\
\hline \hline
\end{tabular}

Fonte: resultados da pesquisa (2019).

Considerando que no perfil sociodemográfico dos apenados constatou-se que aproximadamente metade das pessoas pesquisadas estava trabalhando, ganhando mormente entre um e quatro salários mínimos, com baixa formação educacional, há relação das dificuldades financeiras salientadas na Tabela 2 com as motivações "ajudar no orçamento familiar, estando desempregado" e "dificuldade financeira/endividamento".

Contudo, o motivo da ideia de ganho fácil/indução de amigos/cobiça, ambição, ganância/inveja/manter o status, também relatados por Borilli (2005), Shikida (2005), Santos, Casagrande e Hoeckel (2015) e Schlemper (2018), obteve destaque ímpar. A despeito das dificuldades de ordem financeira destacadas nas motivações para a prática delituosa, no envolvimento em um ato ilegal, de acordo com Santos, Casagrande e Hoeckel (2015, p. 318), a pessoa responde aos incentivos econômicos "a partir da avaliação racional entre ganhos e perdas esperadas, advindos das atividades ilícita vis-à-vis o ganho alternativo no mercado legal, levando em conta sua aversão ou não aos riscos envolvidos na atividade ilegal”. Logo, a motivação consubstanciada na ideia de ganho fácil/indução de amigos/cobiça, ambição, ganância/inveja/manter o status, está também relacionada com a avaliação racional que as pessoas propensas ao crime econômico fazem dos ganhos e perdas esperadas advindas de uma atividade ilícita (do ponto de vista financeiro).

Vale destacar, ainda, que "ajudar no orçamento familiar, mas estando empregado" tem uma relação implícita com a tríade "cobiça, ambição, ganância" mais do que com a dificuldade de ordem econômica, haja vista a observação in loco durante a aplicação do questionário junto aos apenados, sobretudo em função de muitos pesquisados salientarem terem suas necessidades de bens e serviços satisfeitas, porém, ambicionavam sempre mais, na ânsia por ganhos exacerbados.

Destarte, os incentivos para a prática delituosa de caráter pessoal agrupados para esse tipo de pesquisados ("ideia de ganho fácil/indução de amigos/cobiça, ambição, ganância/inveja/manter o status", mais "ajudar no orçamento familiar, porém, estando empregado", mais "falta de estrutura familiar/inconsequência e desejo de aventura", mais "manter 

no paraná. DOI: http://dx.doi.org/10.5380/recp.v10i2.68818

o sustento e vício”, mais “motivos fúteis”) perfazem 63,4\%. Já os incentivos para a prática ilícita de ordem econômica ("ajudar no orçamento familiar, pois estava desempregado", mais "dificuldade financeira/endividamento"), perfazem 62,1\%. Nota-se, portanto, uma divisão desses dois blocos bem próxima em termos percentuais.

Nesse sentido, a presente pesquisa tem como objeto outro perfil de criminoso (que tiveram penas alternativas), mostrando uma conjuntura um pouco distinta de Shikida (2010), que apontou que muitos delinquentes migraram para o ilícito econômico por motivos como a cobiça, ambição, ganância e ideia de ganho fácil, visto terem renda suficiente para saciarem seus desejos de consumo. A pesquisa atual ressaltou um percentual relevante de pessoas com dificuldades de ordem financeira para o cometimento da prática criminosa de crimes considerados "mais leves" e, portanto, mais suscetíveis desse tipo de pena alternativa. Ou seja, a distância entre um bloco e outro diminuiu.

Também foram abordados juntamente com os apenados os fatores que levaram a sua apreensão e detenção, qual seja, o insucesso da prática criminosa.

A maioria dos entrevistados $(86 \%)$ declarou que a ação da polícia foi o principal motivo para o insucesso da operação delituosa. A falha própria foi citada por $5 \%$ como causa do seu malogro. Vale destacar, diante desses dados, a eficácia dos trabalhos da polícia nas prisões e combate ao crime econômico. Tal evidência de fatores que levaram ao insucesso da atividade criminosa, dando crédito às ações policiais, também foi observada por estudos similares - como Borilli (2005) e Schlemper (2018), por exemplo. Entrementes, o percentual de sucesso da ação policial foi maior no presente trabalho que, frisa-se, tem o diferencial de ter apenados de penas alternativas.

Ademais, foi perguntado aos apenados se acreditam no sistema judiciário e $84,2 \%$ disseram acreditar. As tentativas de fugas foram minoritárias, sendo que 6,8\% tentaram fuga, 89,6\% não tentaram e 3,6\% não responderam. A maioria dos entrevistados $(91 \%)$ se disse feliz e $9 \%$ não feliz.

Ainda foram questionadas quais medidas deveriam ser tomadas para diminuir a criminalidade econômica no Brasil. A Tabela 5 traz as respostas sumarizadas dos apenados. De acordo com as respostas, os fatores mais importantes para diminuir o crime econômico foram: mais emprego (47,7\%); mais fiscalização (19,4\%); estudo (7,7\%); e menos impostos (7,2\%). O principal fator apontado pelos entrevistados está em conformidade com Shikida e Brogliatto (2008) e Zacarias (2015), pois o trabalho é importante tanto como valor moral e material em sociedade, na qual a qualidade profissional também possibilita a ascensão no meio social do reeducando na substituição da pena por prestação de serviço ou pecuniária. Vale salientar que uma parcela 

no paraná. DOI: http://dx.doi.org/10.5380/recp.v10i2.68818

expressiva cometeu o crime devido às dificuldades de ordem econômica, muitos para ajudar no orçamento familiar porque estavam desempregados.

Foi feita a seguinte questão aos pesquisados: o que você mais teme/receia quando vai fazer uma atividade criminosa, cite apenas duas opções e em ordem de importância $\left(1^{\mathrm{a}}\right.$ e $2^{\mathrm{a}}$ colocações, respectivamente)? Para Becker (1968), isso pode estar influenciando a questão de ser amante ou avesso em relação ao risco do ilícito lucrativo. Nesse contexto, o maior percentual demonstrou a perda da moral em 41,4\%. Como o maior receio foi o da perda da moral, pode-se relacionar ao trabalho de Schlemper (2019), que destaca a importância do caráter, do conceito de cidadão digno e da moral como fator diferencial que inclui o indivíduo em uma sociedade com pessoas de bem. Destarte, embora as pessoas pesquisadas tenham cometido um crime, ainda persiste em alguns a preocupação com a sua "reputação", sobretudo diante dos familiares mais próximos (como filhos, pais, entre outros). Na segunda colocação apontada pelo pesquisado, o percentual maior de receio ficou com a probabilidade de ser preso em 28,8\%.

Algumas questões adicionais levantadas pelo questionário aplicado visam definir melhor o perfil do agente delituoso em face de temas correlatos. Sobre a redução da maioridade penal, por exemplo, $87,4 \%$ responderam que são a favor da redução, $11,3 \%$ são contra e 1,4\% não responderam. Quando salientado os crimes hediondos, $88,7 \%$ dos entrevistados foi favorável a redução da maioridade penal. Sobre o fato de a lei de maioridade vigente contribuir para os menores cometerem crimes antes dos 18 anos, 88,3\% disseram que a lei contribui para o cometimento de crimes na adolescência, 10,4\% não acreditam que a lei tem influência na criminalidade e 1,4\% não responderam.

Com relação à tentativa de recuperação do menor no Centro de Socioeducação (CENSE), $73,4 \%$ afirmaram que os menores não são recuperados pela entidade; apenas 19,8\% acreditam nessa recuperação; e 6,8\% não responderam. Sobre a legalização das drogas, a maioria dos apenados é contra a legalização $(90,5 \%)$, sendo $9,5 \%$ dos apenados favoráveis apenas à legalização da maconha.

A expectativa média de vida de uma pessoa (ativa) no mundo do crime, segundo respostas dos entrevistados, foi em torno de 23 anos de idade. Isso aponta para um fato interessante, porquanto, embora o crime tenha sido lucrativo para a maioria daqueles que o cometeram, a expectativa média de vida da pessoa que tem esse perfil é considerada baixa. Desse modo, se o crime está compensador do ponto de vista financeiro, segundo resultado da análise custo-benefício, o seu aproveitamento em vida retrata um reduzido tempo de existência para usufruir desse resultado. Ressalta-se a questão: vale a pena? 

no paraná. DOI: http://dx.doi.org/10.5380/recp.v10i2.68818

Diante do contexto atual dos crimes econômicos tipificados, foi muito pertinente perguntar se o apenado trabalhava por conta própria (free lance) ou se foi contratado por algum "patrão" ou organização. No caso de a resposta ser positiva, ainda foi perguntado se fazia parte do "acordo" algum tipo de auxílio para o caso de ser preso (por exemplo: contratação de advogado, pagamento de fiança, ajuda para a família, etc.). Verificou-se que 55,9\% (124 apenados) afirmaram ter "patrão", 41,9\% (93) trabalhavam por conta própria e 2,3\% (5) não responderam. Dos 124 apenados que responderam ter "patrão", 67,7\% (84) realizaram o ato ilícito somente pelo pagamento do serviço, sendo que 32,3\% (40) havia combinado com o contratante auxílios como fiança, advogados ou qualquer ajuda financeira, caso houvesse prisão. Destes 40, 18 (45\%) tiveram o combinado "honrado" e 22 (55\%) foram "enganados" (termo este unívoco usado pelos respondentes durante a entrevista) pela organização.

Como destaque do perfil criminal, o custo/benefício na prática do crime econômico, a partir da própria percepção dos entrevistados, teve uma média de custos de 1,01, ante a média de ganho de 3,35. Com saldo positivo médio de 2,34 do benefício sobre o custo, os entrevistados confirmaram a escolha racional de migração para o setor ilegal da economia sendo lucrativa. Esse corolário foi constatado em estudos similares que também se basearam na teoria de Becker.

Sumariando, o conjunto das características dos apenados pode ser assim descrito: o crime mais praticado foi o de contrabando (sendo que alguns cometeram mais de um tipo de crime), tendo como principal motivação para o crime econômico a ideia de ganho fácil/indução de amigos/cobiça, ambição, ganância/inveja/manter o status (46,1\%), sendo a ação policial o principal insucesso da atividade criminosa. A maioria acredita na justiça, aprova a redução da maioridade penal, pois acredita que a lei atual contribui para o cometimento de crimes por parte dos menores infratores. O maior receio dos apenados $\left(1^{\mathrm{a}} \mathrm{e} 2^{\mathrm{a}}\right.$ colocações) apontou, respectivamente, para a perda moral e a probabilidade de ser preso.

Como aspectos adicionais, sobre o fato de a prestação de serviço ser adequada à formação do entrevistado, cerca de $72,1 \%$ dos pesquisados disseram que sim, 27,5\% responderam que o trabalho prestado não é compatível com a sua formação, e 0,5\% não responderam. Quando perguntados sobre o motivo da resposta ser positiva, os apenados disseram, com mais frequência, que a prestação de serviço é: "adequada", "por ser bem distribuída”; "a pessoa faz o que sabe, contribuindo assim para um desempenho melhor nos afazeres que a entidade receptora precisa". Em relação ao percentual negativo, as respostas que mais sobressaíram foram: "dificuldade com o deslocamento até as entidades"; "falta de aptidão"; e "os horários da prestação de serviços com o trabalho do dia a dia dificultam a assiduidade". 

no paraná. DOI: http://dx.doi.org/10.5380/recp.v10i2.68818

Quando interrogados se o tipo de serviço prestado é útil à sociedade, a maioria disse que $\operatorname{sim}(80,6 \%), 18,5 \%$ não e apenas $0,9 \%$ dos entrevistados não se manifestaram. Frente aos principais motivos dos apenados que responderam que o tipo de serviço prestado é útil à sociedade, têm-se: "ajuda nas necessidades das receptoras"; "fica em dia com a sociedade e sente-se seguro ao prestar serviço ao invés de estar preso". Dos apenados que responderam negativamente, foi apontado que: "acreditam que o serviço prestado não é útil por ser obrigação legal do Estado em fornecer esses serviços às entidades receptoras".

Sobre a prestação pecuniária do condenado, foi solicitado definir quais os pontos positivos deste tipo de pena, sendo assinalados: "não estar preso"; "cumprir a lei"; "ajuda a sociedade". Como pontos negativos, destacaram-se: "valor alto"; “dói no bolso"; "voltam para o crime”; e "já pagam em serviço".

Como foram 161 pessoas que tiveram condenações de prestação pecuniária dos 222 pesquisados, a pergunta se o valor estipulado pelo juiz da prestação pecuniária era justo foi direcionado aos diretamente afetados. Logo, responderam que não foi justo $68,9 \%, 25,5 \%$ que sim, 5,6\% optaram em não responder. Interrogado de o porquê não ser justo o valor estipulado pelo juiz, a maioria dos respondentes disseram ser um valor elevado para seus padrões financeiros. Também foi requerido sobre os valores que os apenados tinham obrigação de pagar, sendo o valor médio apontado por eles de $\mathrm{R} \$ 11.291,46$.

\section{CONSIDERAÇÕES FINAIS}

O objetivo desta pesquisa consistiu em analisar o perfil sociodemográfico e criminal de apenados que cumprem sentença no âmbito da $4^{\text {a }}$ Vara da Justiça Federal de Foz do Iguaçu (Paraná), por crimes praticados de ordem econômica cujas penas privativas de liberdade foram substituídas por prestação de serviços e/ou prestação pecuniária.

O perfil sociodemográfico dos pesquisados evidencia a predominância do sexo masculino nascidos nos estados do Paraná e do Rio Grande do Sul, de cor branca e origem urbana, se dizem majoritariamente católicos, a maioria praticante da religião que professaram, enquanto o maior contingente dos entrevistados estava amasiado. O nível de instrução com maior frequência foi o ensino fundamental, interrompido por motivos como a necessidade de contribuição à renda familiar.

O perfil criminal dos pesquisados evidencia o contrabando (em sua maioria de cigarro) como o delito de maior ocorrência (52,7\%), sendo que a principal motivação para o crime econômico está relacionada com a ideia de ganho fácil/indução de amigos/cobiça, ambição, 
ganância/inveja/manter o status (46,1\%). O custo do ilícito foi menor do que o seu retorno econômico.

Mediante ao exposto, resta mencionar que compete ao Estado atentar para as travas morais ("família-escola-religião"), efetivar investimento na educação, oportunizar trabalho lícito, evitando os crimes econômicos e aplicando as normas constitucionais em respeito à dignidade da pessoa.

Pelo fato de a pesquisa se utilizar de dados primários, abre-se caminho para novos trabalhos acadêmicos com relação ao objetivo deste, buscando conhecer a realidade pública e social dos apenados submetidos à prestação de serviço em substituição da pena privativa de liberdade, bem como da prestação pecuniária.

O presente trabalho trouxe contribuições com evidências empíricas para os magistrados referente às implicações da substituição das penas privativas de liberdade em prestação de serviço. Assim, futuras decisões judiciais podem levar em consideração os fatores levantados nessa pesquisa e que corroboram para uma efetiva ressocialização.

Além de auxiliar nas decisões judiciais, os resultados desta pesquisa podem servir de apoio aos legisladores para atualizar o CP, no sentido de se aplicar a substituição de pena para outras modalidades de condenações (por exemplo, o regime fechado), com o intuito de se reduzir a superlotação carcerária, bem como promover a reintegração social.

Isso posto, como este estudo seguiu um determinado rumo metodológico dentre vários possíveis, fica como sugestão para trabalhos vindouros avançar nessa temática mediante novas incursões não só de tratamento metodológico, mas também de outras delimitações geográficas (novos casos, que podem envolver cidades e/ou estados) ou, quem sabe, pesquisando/ouvindo a outra face diretamente vinculada com as penas privativas de liberdade que foram substituídas por prestação de serviços e/ou prestação pecuniária, que é o poder judiciário.

\section{REFERÊNCIAS}

ARISTÓTELES. (1992). Ética a Nicômaco. 3. ed. Tradução de Mário da Gama Kury. Brasília: Universidade de Brasília.

BALBINOTTO NeTO, G. (1993). Gary Becker: Prêmio Nobel de economia de 1992. Análise Econômica, vol. 11, n 19, p. 188-191.

BECCARIA, C. (2007). Dos delitos e das penas. São Paulo: Martin Claret.

BECCARIA, C. (1997). Dos delitos e das penas. Tradução de J. Cretella Jr. e Agnes Cretella. São Paulo: Revista dos Tribunais. 
BECKER, G. S. (1968). Crime and punishment: an economic approach. Journal of Political Economy. vol. $76, \mathrm{n}^{\circ} 1$, p. 169-217.

BERGER, L. M. (2008). Um modelo baseado em agentes para estudo das propriedades emergentes decorrentes da aplicação da lei penal. Porto Alegre. Dissertação (Mestrado em Administração). Universidade Federal do Rio Grande do Sul.

BITENCOURT, C. R. (2017). Falência da pena de prisão: causas e alternativas. 5. ed. São Paulo: Saraiva.

BITENCOURT, C. R. (2019). Tratado de Direito Penal. 25. ed. São Paulo: Saraiva, v. 1.

BORILLI, S. P. (2005). Análise das circunstâncias econômicas da prática criminosa no Estado do Paraná: estudo de caso nas penitenciárias Estadual, Central e Feminina de Piraquara. Toledo. Dissertação (Mestrado em Desenvolvimento Regional e Agronegócio). Universidade do Oeste do Paraná.

BRASIL. (2017). Código de Processo Penal (1941). In: CÉSPEDES, L., ROCHA, F. D. da. (Orgs.). Vade Mecum Saraiva OAB e concursos. 11. ed. São Paulo: Saraiva. p. 595-650.

BRASIL. (2017). Código Penal (1940). In: CÉSPEDES, L., ROCHA, F. D. da. (Org.). Vade Mecum Saraiva $O A B$ e concursos. 11. ed. São Paulo: Saraiva, XI. p. 509-553.

BRASIL. (2017). Constituição da República Federativa do Brasil (1988). In: CÉSPEDES, L., ROCHA, F. D. da. (Org.). Vade Mecum Saraiva OAB e concursos. 11. ed. São Paulo: Saraiva, XI, p. 577.

BRASIL. (2017). Decreto Lei no 3.914/1941, de 9 de dezembro de 1941. In: CÉSPEDES, L., ROCHA, F. D. da. (Org.). Vade Mecum Saraiva OAB e concursos. 11. ed. São Paulo: Saraiva, XI, p. 485.

BRASIL. (2017). Lei de Execução Penal (1984). In: CÉSPEDES, L.; ROCHA, F. D. da. (Org.). Vade Mecum Saraiva $O A B$ e concursos. 11. ed. São Paulo: Saraiva, XI, p. 1525-1542.

BRASIL. Superior Tribunal de Justiça. (2010). Recurso Especial n 1.107.314/PR, Brasília, 13 de dezembro de 2010. Disponível em <http://www.stj.jus.br/webstj/processo/justica/detalhe.asp? numreg $=200802824428>$. Acesso em: 20 de abr. de 2019 .

CARNELUTTI, F. (2006). As misérias do processo penal. São Paulo: Pillares.

CERQUEIRA, D.; LOBÃO, W. (2004). Determinantes da criminalidade: arcabouços teóricos e resultados empíricos. DADOS - Revista de Ciências Sociais, Rio de Janeiro, vol. 47, n 2, p. 233-269.

CONSELHO NACIONAL DE DESENVOLVIMENTO CIENTÍFICO E TECNOLÓGICO (CNPq). (2018). Edital Universal 2018. Disponível em

<http://www.cnpq.br/web/guest/chamadas-

publicas?p_p_id=resultadosportlet_WAR_resultadoscnpqportlet_INSTANCE_0ZaM\&filtro=en cerradas\&detalha $=$ chamadaDetalhada\&exibe $=$ exibe\&idResultado $=47-1191-5774 \& i d=47-1191$ 5774>. Acesso em: 11 de jul. de 2019.

FANTINEL, G. A. (2016). A ineficácia da função ressocializadora da pena privativa de liberdade. Santa Maria. Monografia. (Graduação em Direito). Universidade Federal de Santa Maria. 
NICKEL, H.; SHIKIDA, P. F. Uma análise dos apenados por prestação de serviços elou pecuniária no paraná. DOI: http://dx.doi.org/10.5380/recp.v10i2.68818

GIL, A. C. (2000). Técnicas de pesquisa em economia e elaboração de monografias. São Paulo: Atlas.

GOMES, L. F. (2000). Penas e medidas alternativas à prisão: doutrina e jurisprudência. 2. ed. São Paulo: Revista dos Tribunais.

GRECO, R. (2019). Curso de Direito Penal: parte geral. 21. ed. v. 1, Rio de Janeiro: Impetus.

MASSON, C. (2020). Direito Penal Esquematizado: parte geral. 14. ed. São Paulo: Método.

MIRABETE, J. F., FABBRINI, R. N. (2018). Manual de Direito Penal. 34. ed. rev. e atual. São Paulo: Atlas.

MOREIRA, R. de A. (2015). O Conselho Nacional de Justiça e as penas alternativas. Conteúdo Jurídico, Brasília-DF: 31 jan. 2015. Disponível em:

<http://www.conteudojuridico.com.br/?artigos\&ver=2.52337>. Acesso em: 11 de abr. 2019.

NICKEL, H. 2019. Análise da execução penal envolvendo crimes econômicos no Paraná cuja pena privativa de liberdade foi substituída por prestação de serviços el ou pecuniária. Toledo. Dissertação (Mestrado em Desenvolvimento Regional e Agronegócio). Universidade Estadual do Oeste do Paraná.

NUCCI, G. de S. (2019). Código Penal Comentado. 19. ed. São Paulo: Editora Forense.

PASTORE, J. (2011). Trabalho para ex-infratores. São Paulo: Saraiva.

SANTOS, C. dos, CASAGRANDE, D., HOECKEL, P. (2015). “Teoria econômica do crime": dos pressupostos acadêmicos à empiria do dia a dia na vida de ex presidiários de Santa Maria RS. Revista Economia e Desenvolvimento, Santa Maria, vol. 27, n² 2, p. 308-325, jul./dez.

SANTOS, W. (2001). Dicionário Jurídico Brasileiro. Belo Horizonte: Del Rey.

SCHLEMPER, A. L. (2018). Economia do crime: uma análise para jovens criminosos no Paraná e Rio Grande do Sul. Toledo. Tese (Doutorado em Desenvolvimento Regional e Agronegócio). Universidade Estadual do Oeste do Paraná.

SHECAIRA, S. S. (2008). Sistema de garantias e o direito penal juvenil. São Paulo: Revista dos Tribunais.

SHEPSLE, K. A. (2008). Rational choice institutionalism. In: RHODES, R. A. W., BINDER, S. A., ROCKMAN, B. A. (Orgs). The Oxford book of political institutions. Oxford: Oxford University Press, p. 23-38.

SHIKIDA, C. D.; ARAUJO JUNIOR, A. F. D.; SHIKIDA, P. F. A. (2005). A moral importa? Revista de Economia e Administração, São Paulo, vol. 4, n 4, p. 415-426, out./dez.

SHIKIDA, P. F. A. (2010). Considerações sobre economia do crime no Brasil: um sumário de 10 anos de pesquisa. Revista de Análise Econômica do Direito/Economic Analysis of Law Review, vol. 1, $\mathrm{n}^{\circ} 2$, p. 318-336, jul./dez.

SHIKIDA, P. F. A. (2005). Economia do crime: teoria e evidencias empíricas a partir de um estudo de caso na Penitenciária Estadual de Piraquara (PR). Revista de Economia e Administração, São Paulo, vol. 4 , n 3, p. 315-342, jul./set. 
SHIKIDA, P. F. A., BROGLIATTO, S. R. M. (2008). O trabalho atrás das grades: um estudo de caso na Penitenciária Estadual de Foz do Iguaçu - PR. Revista Brasileira de Gestão e Desenvolvimento Regional, Taubaté, vol. 4, n 1(4). p. 128-154, jan./abr.

VARA DE EXECUÇÃO DE PORTO VELHO/RO. (2019). Disponível em: < http://ambitojuridico.com.br/site/?n_link=revista_artigos_leitura\&artigo_id=14998>. Acessado em: $10 \mathrm{de}$ abr. 2019.

ZACARIAS, A. E. de C. (2015). Manual do Criminalista - Lei de Execução Penal - Anotada e Comentada. 2 ed. São Paulo: Edijur. 